\title{
MODELS INTERDISCIPLINARY LEARNING FOR PRIMARY EDUCATION (OR: WHAT ELSE TO KNOW AND CAN STUDENTS?)
}

\author{
R. Neminska* \\ Faculty of Education, Trakia University, Stara Zagora, Bulgaria
}

\begin{abstract}
The article examines the problem of a new approach to learning. This approach is associated with the understanding of interdisciplinary teaching. Interdisciplinary learning is seen through the prism of two concepts: that of integration and that the individual discipline.

The main thesis is that students need to develop interdisciplinary skills as a high degree of professional skill. An example of a structure for planning an interdisciplinary unit in primary education. In this structure, each student can develop professional creativity.

Presented are examples of methodological resources, interdisciplinary approach and interdisciplinary learning.

Similar methodological resources are used in the learning of students teachers.
\end{abstract}

Key words: interdisciplinary lessons, interdisciplinary learning, interdisciplinary skills.

\section{FOR INTERDISCIPLINARY LEARNING. DEFINITION OF THE PROBLEM}

In a world of multiple information network, education at all levels to develop interdisciplinary knowledge and relationships. Today, interdisciplinary training at all levels is far more successful and promising. There is growing recognition that it is necessary to address the complex issues in solving complex problems; to get a clear understanding of the complex issues that are increasingly beyond the ability of any single discipline to address comprehensively or adequately resolve. As some authors $(1$, p.7) research real-world problems are such that rarely occur within separate disciplinary categories, nor in their decisions." In science define concepts for interdisciplinary research, whose main concepts are interdisciplinarity and integration.

\section{Integration and interdisciplinarity}

Integration literally means to make whole. In the context of interdisciplinarity, integration is the process by which ideas, data and information, methods, tools, concepts and / or theories of two

${ }^{*}$ Correspondence to: Rumyana Neminska, Faculty of Education, Trakia University - Stara Zagora, Bulgaria,neminska@abv.bg or more disciplines are synthesized related or mixed.

Some experts understand interdisciplinarity as "any form of dialog interaction between two or more disciplines", while minimizing or completely reject the role of integration $(2, \mathrm{p}$. 14) On the other hand, it is believed that the interaction should be the purpose of the interdisciplinary research and training. The reason is that integration raises the challenge of complexity. Integrationists talk about the growing importance of integration as a link in interdisciplinary education and research. In their theories reduces semantic evasiveness, surrounding the term and interdisciplinary research point in cognitive psychology. These professionals displayed integrational understanding of interdisciplinarity as unification. Integration and interdisciplinarity. Integration literally means to make whole. In the context of interdisciplinarity, integration is the process by which ideas, data and information, methods, tools, concepts and / or theories of two or more disciplines are synthesized related or mixed.

Some experts understand interdisciplinarity as "any form of dialog interaction between two or 
more disciplines", while minimizing or completely reject the role of integration $(2, \mathrm{p}$. 14) On the other hand, it is believed that the interaction should be the purpose of the interdisciplinary research and training. The reason is that integration raises the challenge of complexity. Integrationists talk about the growing importance of integration as a link in interdisciplinary education and research. In their theories reduces semantic evasiveness, surrounding the term and interdisciplinary research point in cognitive psychology. These professionals displayed integrational understanding of interdisciplinarity as unification.

"Discipline" as the basis of interdisciplinary research. The term discipline refers to a specific branch of study or body of knowledge, such as physics, psychology or history (2, p.2). According to the American Association for Higher Education and Accreditation (AAHEA), the courses are contrast agents and syntaxways of self-organization. They have different ways of presenting the problems, issues and questions. The researchers added that "each discipline has its own intellectual history, agreements and disputes the object and methods" and their "community" of scientists. Interested in teaching and learning in this area." (3) Disciplines also differ from one another by several factors disciplinary questions about the world, their outlook or worldview, a set of assumptions used methods used to establish a body of knowledge (facts, concepts, theories) about a particular subject. Today the line between individual disciplines and interdisciplinary approach as has begun to blur. In recent years the emergence of interdisciplinary fields. These are areas of knowledge that cross traditional disciplinary knowledge and include a wide variety of interactions ranging from informal groups of scholars who are well established research and educational communities. Often cited examples of interdisciplinary sciences environmental science, nanotechnology, psycholinguistics, ethnomusicology, cultural studies, women's studies, urban studies. (3). Interdisciplinary areas differ from private disciplines in terms of their origin, nature, status and level of development. For example in teaching science can be considered interdisciplinary areas such as pedagogy of tolerance, knowledge of religion as a cultural fact and many others. etc. Applied disciplinary fields are not solid and unchangeable. They develop social and intellectual constructs, and as such are a reflection of contemporary social problems. This means that today's discipline may have been a separate discipline or branch of an existing discipline. It can also talk about a "hidden reality of interdisciplinarity" where interdisciplinarity flourish, but not labeled. In this case the model of interdisciplinary research is the following:

1. Researchers separate subject or object from existing disciplinary frameworks;

2. Fill gaps in knowledge from disciplines;

3. Redefining new space knowledge and new professional roles $(3$, p. 36-37).

The word interdisciplinary consists of two parts: inter- and disciplinary. Prefix meaning "between, right, middle, or obtained by two or more. The other part of the word - "disciplinary" means related to a field of study or specialization. So the starting point for determining the interdisciplinary between two or more areas of knowledge. "Inter" refers to the disputed area, the space "in between." Interdisciplinary study examines the issue or issues that are the focus of several disciplines.

The main characteristic of interdisciplinary study is that the subjects are not the focus of interdisciplinarity. Focus is the problem, question or intellectual part with which each discipline is concerned. The courses are simply a means to that end. Interdisciplinary can refer to and "Insights The thing derived from two or more fields of study. Action taken on these insights by interdisciplinary enter into symbiosis. Integrative process here involves creating a field of conflict-free insights into the particular problem of two or more disciplines.

"Inter" refers to the result of integration. The result of integration is another aspect of prefixinter. Means something completely new, distinctive, beyond any discipline. Thus achieves cognitive development or addition to knowledge of disciplines. This product interdisciplinary symbiosis implies and leads to a more complete understanding or a more comprehensive theory. This understanding can be used for various purposes, including the formulation of new policies, new framing research questions.

Development of new aspects and paths in scientific knowledge and methodological knowledge is closely related to the skills of students as teachers of the future. In this sense, it is necessary their narrow disciplinary skills to develop and exercise wider. To fashioning skills 
to master and develop interdisciplinary trajectories of knowledge and methods of interdisciplinary learning. Development of new aspects and paths in scientific knowledge and methodological knowledge is closely related to the skills of students as teachers of the future. In this sense, it is necessary their narrow disciplinary skills to develop and exercise wider. To fashioning skills to master and develop interdisciplinary trajectories of knowledge and methods of interdisciplinary learning.

\section{WHAT IS INTERDISCIPLINARY LEARNING?}

Interdisciplinary education is one of many ways to study topics from the curriculum. When teachers consider their learning objectives and needs of the students are wider, they can choose interdisciplinary training to provide part or all content. This method can help students to think in new ways meaningful connections between disciplines. Interdisciplinary skills that students can develop in his academic training may cover a number of disciplines. The focus among these is the problem, case studies, alternative decisions. This interdisciplinary approach, students will synthesize their learning by pointing to set evidence from multiple disciplines. They could respond in various ways, such as making a comparison of the relative truth. (4)

The educational process in the so-called interdisciplinary training: learning - cycle has its specifics. Interdisciplinary unit examined and commented on the prospects of multiple disciplines. An important trend is for students to focus on knowledge of values and belief generalizations. The aim is to create an interdisciplinary link between several disciplines. As this process is not only important what they do and know studetite, but the knowledge that their offers teacher. So this knowledge to sanctify them.

To set goals, standards, the themes of interdisciplinary learning thoroughly, you need to understand that this is one of many approaches to designing and teaching the curriculum. To be effective interdisciplinary unit, it must be designed properly. Curriculum begins as pre-formatted package of necessary elements and recommendations for training for a particular grade level, semester or year. A good curriculum expands on this guide and becomes a training project. Educational projects and plans are tailored to the needs of the real world in which communicate and develop students.

The content of educational programs include interdisciplinary topics, questions, problems which are becoming involved in training. Criteria for assessing the skills and thought processes change. They are directed towards the development and implementation of appropriate training techniques. So students develop critical thinking skills, reading comprehension, analysis, mathematical skills and skills for valuables. Evaluation in interdisciplinary teaching is directed to products and results that demonstrate skills and thinking. Products can be pedagogical essays, projects, taking notes, case studies, etc.

In general methodical plan interdisciplinary training can be structured in the following

Step 1: Planning process. Selecting the format and justification of choice.

Step 2: Project title and organizational center. Working title of the interdisciplinary unit. It reflects the priorities identified in the assessment of needs. It can serve as an organizing center for the unit.

Step 3: Brainstorm to use the concept. Drawing conceptual circle in the middle and vpisvayne each discipline that you plan to view. Place the organizing center you selected in step 2 in the center of the wheel.

Step 4: Develop the essential questions. Development of the main issues, structural building blocks of the interdisciplinary unit. The main issues in the interdisciplinary unit help students discover the natural links between specific areas of the disciplines involved. The best units are guided by the fundamental questions that lead across multiple disciplines. So students acquire skills to ask the same question from different perspectives.

Step 5: Integrating skills assessments and substantive issues. This is the main point, which balance the goal, themes, skills assessments with content. Here seen to integrate standards.

Step 6: Planning the day to day activities. The steps that students will realize the acquisition of certain skills. The aim is to develop a schedule that directly connects each activity with a specific substantive issue.

Step 7: Self: Rubric to review the design of interdisciplinary unit. Important elements of assessment include: 1. Justification - identifying the reasons for selecting an interdisciplinary design; 2. Meaningful and effective relationships with other disciplines. Study links with other disciplines; 3. Purpose and benefits for the specific needs of the student; 4. Scope of 
engagement of human and technological resources.

\section{METHODOLOGICAL RESOURCES}

The proposed methodological resources are interdisciplinary lessons nominated as innovative school practices by the Ministry of Education in Bulgaria and Information Office of the European Union. They are built on taxonomic and methodological framework, which allows to develop different educational content. Therefore these and similar nominees methodological resources serve as models for training students. This connection of proven innovative school practice with the academic preparation of students - educators develop a new type of professional skills. These skills are of higher rank methodical and interpreted by the author as interdisciplinary skills. (5)

\section{METHODOLOGICAL RESOURCE: KNOWLEDGE FOR THE HOLIDAYS -A WAY TO TOLERANCE AND UNDERSTANDING (TOPIC ONE)}

Cultural and educational field: "Social Science and Civic Education Study subject:" Man and Society "- third class.

Subject of the lesson: "Holidays and traditions of Bulgarian citizens." "Virtual Christmas"; type of lessons - summary

Lesson plan: Goal: Opening of wealth in intercultural and religious traditions. Expansion and clarification of knowledge about domestic traditions of Christmas Eve. Expansion and clarification of knowledge about the spiritual nature of Christmas celebration - "Nativity". Developing the skills to work with a computer as a prerequisite and necessary for modern communication.

Tasks: 1. Students get acquainted with some of the holidays in Bulgaria ethno-cultural space. 1.1. Using the reading skills of narrative text "letter", students receive information about an unknown holiday.

2. Work assignment - Students introduce (write) a letter to a student from another religion, using knowledge for the Christmas holidays. 2.1. To determine the work program; to introduce: font, color, size of letters asked the teacher.

3. Work on the project - students through computer graphics, draw greeting card in a certain artistic model. 3.1. To determine the work program; to determine the algorithm of the operation, according to the technique of the embodiment.
4. Work on the project - students through computer graphics to draw a picture on a certain winter children's song. 4.1. To determine the work program; to determine the algorithm of the operation, according to the technique of the embodiment.

Preparation. Methodological:

1. Visit the three temples in the city center - a church, mosque, synagogue. Getting to know the history, architecture and rituals in every temple.

2. Students have developed skills for working in groups.

3. Survey of additional educational literature. Technical: Technical cabinet prepared to listen to music and implementation of educational tasks and products to students.

Educational highlights in the lesson: 1. Update knowledge from observation made in the three temples - visit a synagogue, mosque, church. Reading a letter from each group.

2. Focus of the upcoming Christmas holidays and determination as a Christian.

3. Allocation of group tasks:

- Writing a letter - for the holiday Christmas Eve; Christmas feast.

- Drawing on music - four children's songs.

- Drawing on the model - four cards ready.

4. Exercise and develop computer skills in order to obtain an educational product related to the topic - a letter and a postcard picture.

5. Strengthening skills for selecting algorithms work.

6. Strengthening and summarizing computer skills to create virtual Christmas holiday.

\section{METHODOLOGICAL RESOURCE: KNOWLEDGE FOR THE HOLIDAYS -A WAY TO TOLERANCE AND UNDERSTANDING (TOPIC TWO)}

Subject of the lesson: "Holidays and traditions of Bulgarian citizens." 2. "Winter Holidays"

Cultural and educational field: "Civics and citizenship education.

Cultural and educational field, "Information Engineering"

Subjects "Man and Society"; ITT "Working with computer" - the EPA;

Type of lesson: summary.

Purpose: Expansion and clarification of knowledge about traditional winter holidays in Bulgaria; Expansion and clarification of knowledge about Bulgaria's accession to the EU through the knowledge of the diversity of holidays; Develop practical skills for working with application software; Improving and 
applying skills in a new context for working with computer systems and information technology. Tasks: 1. Expanding knowledge about holidays in Bulgaria ethno-cultural space.1.1. Using the reading skills of narrative text - "letter" students to expand their knowledge of customs and holidays of three communities - Jewish, Christian, Muslim. 1.2. Expanding importance of meaningful concepts: "community", "nationals" (empirical level). 1.3. Entering Bulgarian ethnocultural space in Europe's borders; understanding of the empirical level motto "Unity in Diversity". 2. Work assignment - By word processor. 2.1. Determining the work program; introduction: font, color, size of letters asked the teacher. 2.2. Storing information.

3. Project work - Students program through computer graphics to design greeting card on a specific topic. 3.1. To determine the work program; to determine the algorithm of the operation, according to the technique of the embodiment. 3. 2. Preservation of information. 4. Work on the project - students through computer graphics program to construct a picture in a certain winter children's song. 4.1. To determine the work program; to determine the algorithm of the operation, according to the technique of the embodiment. 4.2 .Store information.

Preconditioning. Methodological: Visit the three temples in the city center - a church, mosque, synagogue; develop skills for working in groups; study additional educational literature.

Technical: Technical cabinet prepared to listen to music and implementation of educational tasks and products to students. Educational highlights in the lesson:

1. Update knowledge for Christmas.

2. Updating the knowledge of observation made in the three temple - synagogue, mosque, church. 2.1. Reading a letter from each group.

3. Focus of the traditional winter holidays (name-days) and their designation as Christian. 3.1. New date in Bulgarian holiday calendar 1.01.07, the (accession of Bulgaria to the EU)

Allocation of group tasks: 1.1. Writing a letter of traditional holidays in Bulgaria.

1.2. Drawing on a given topic - "Temples we know"

1.3. Drawing on music (four children's songs), "Winter Musical cards." 1.4. Drawing on a given topic: "Hello, Europe!" 1.5. Exercise and develop computer skills in order to obtain an educational product related to the topic - a letter card. 2. Strengthening skills for selecting algorithms work.

\section{REFERENCES}

1. Carole L Palmer, (2001) Structures and strategies of interdisciplinary science, Journal of the Association for Information Science and Technology.

2. Moran J. ( 2010) Interdisciplinarity (2nd Edition), University of Sussex, UK.

3. Klein, (2005) National Academy of Sciences, National Academy of Engineering, and Institute of Medicine, p. 249-252)

4. Neminska, R. (2015) Interdisciplinary learning, $S$.

5. Neminska, R. (2015) Educational Technology in value, $S$. 